\title{
Experimental analysis of high velocity impacts of composite fragments on aluminium plates
}

\author{
Jorge López-Puente ${ }^{1}$, Jesús Pernas-Sánchez ${ }^{1}$, José Alfonso Artero-Guerrero ${ }^{1}$, David Varas $^{l}$, \\ Joseba Múgica ${ }^{2}$, Claudio $S$. Lopes ${ }^{3}$,Esteban Martino ${ }^{4}$, and Vasilis Votsios ${ }^{4}$ \\ ${ }^{1}$ Department of Continuum Mechanics and Structural Analysis, Universidad Carlos III de Madrid, \\ Avda. de la Universidad 30, 28911 Leganés, Spain, E-mail: jlpuente@ing.uc3m.es \\ ${ }^{2}$ IDOM, Spain \\ ${ }^{3}$ Institute IMDEA Materials, C/Eric Kandel 2, 28906 Getafe, Madrid, Spain \\ ${ }^{4}$ AIRBUS, Spain
}

\begin{abstract}
The improvement of engines is one of the ways to diminish the fuel consumption in civil aircrafts, and Open Rotors engines are one of the best promises in order to achieve a sensible efficiency increment. These engines have large composite blades that could, in the event of failure, impact against the fuselage, totally or partially. In this case, composite fragments could behave as impactors. In order to design fuselages for this event and adopt these new engines in the future, it is necessary to understand the impact behaviour of a composite fragment against a deformable structure. To this end, unidirectional and woven composites fragments were impacted at high velocity (up to $150 \mathrm{~m} / \mathrm{s}$ ) against aluminium panels at different impact velocities. The composite fragments were made using AS4/8552 (UD) and AGP-193PW (woven) prepregs manufactured by Hexcel Composites, both using AS4 fibres and 8552 epoxy matrix. High speed video cameras were used to record the impact process and to measure both the impact and the residual velocity and hence the energy absorbed.
\end{abstract}

\section{Introduction}

The aeronautic transport industry it is responsible of around $2 \%$ of all the greenhouse gasses emitted to the atmosphere. In order to diminish this footprint, and also considering that the fuel cost is one of the most important costs of the airlines, the aircraft engine manufacturers are always trying to improve the efficiency of its developments. One of the most important advances conceived in last years is the open rotor engine, which promises around a $20 \%$ less fuel consume. This new engine consists on a series of large composite blades (around 2 meters tall) acting as propellers; in case of failure these blades could impact the fuselage since these engines doesn't have an structural case. Hence, one of the main issues that aircraft manufacturers have to solve in order to incorporate these new engines, is to assure the structural integrity in case of a failure.

This threat (a composite fan blade impacting against the fuselage) is new for the aircraft industry, since up to now composite fragments were not on the list of possible objects which 
could impact an airliner. This is probably the reason why it is not easy to find articles regarding the behaviour of composite fragments against lightweight structures (typically aluminium or carbon/epoxy laminate plates).

The behaviour of lightweight structures under high velocity impacts of quasi-rigid bodies has been analysed by different authors [1-7]. The authors of this work have also published several works related to this subject [8-14]. By the other hand it is possible to find works in which the projectile it is highly deformable, such as gelatine (synthetic bird) or ice [15-16]. Finally, the study of the behaviour of structures under the impact of frangible impactors (such as composite) it is scarce; one example is the work of Mamalis et al. [17,18] which studied experimentally and numerically the axial compression of composite tubes. More recently Mata-Díaz et al. published two articles analysing the behaviour of composite fragments when impacting on a rigid plate [19-20].

In this work the behaviour of aluminium plates under high velocity impacts of composite fragments has been studied. In order to evaluate the influence of the architecture of the composite, two different laminates were selected (unidirectional and woven). The residual velocity vs. impact velocity curve has been obtained, allowing the determination of the ballistic limit.

\section{Experimental procedure}

In order to perform the experimental tests, a pneumatic launcher was used. An $80 \mathrm{~mm}$ diameter circular barrel tube was modified to accommodate a $44 \times 44 \mathrm{~mm}^{2}$ square tube which will act as a new barrel (Figure 1). Using this setup, the rotation of the composite fragment during the acceleration is avoided, and hence the fragment impact occurs always in the same orientation. At the end of the barrel two laser sensors detect the projectile pass and calculates the impact velocity. A special sabot has been developed in order to accelerate the impactor; it is made using 3-D printing, and it is stopped at the barrel mouth, releasing the fragment.

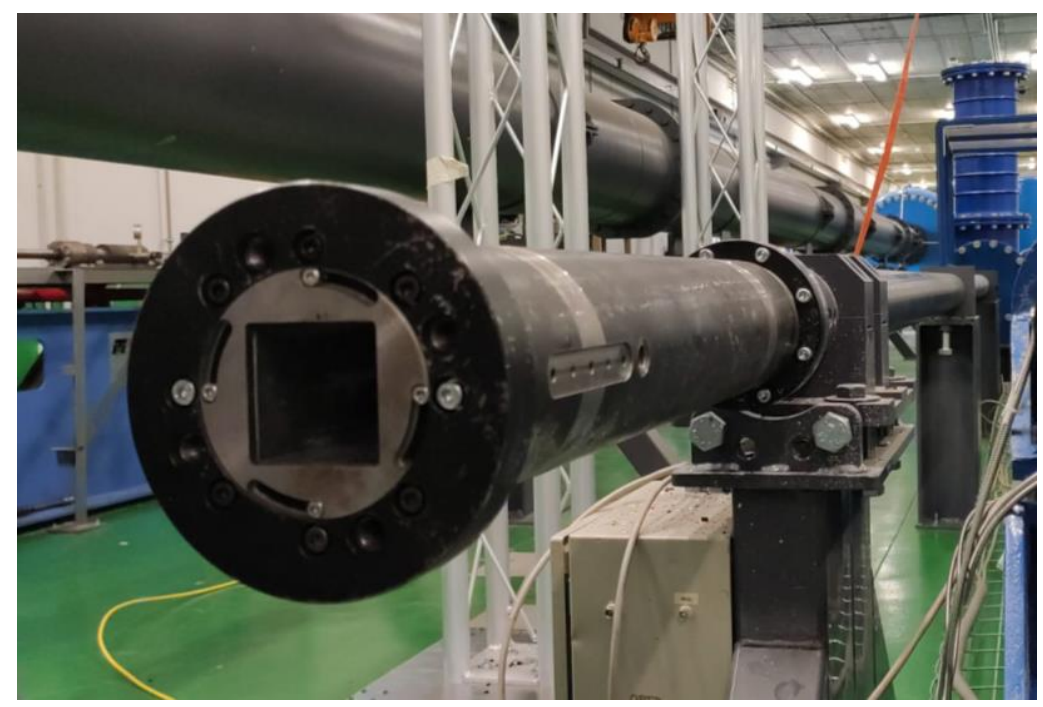

Fig. 1. Pneumatic launcher used to accelerate the composite fragments.

To visualize the impact process, two high-speed Photron video cameras were used. One of them was placed looking at the impact face, whereas the second one was used to observe the 
rear face. In both cases the cameras were configured to capture 20000 frames per second. Lighting was provided by two ArriSun Lamps of $1200 \mathrm{~W}$ each. The images obtained were used to measure the residual velocity of the fragment in case of penetration.

Two different carbon/epoxy composite fragments were considered, one made using tape plies (AS4/8552), being the other manufactured using woven laminas (AGP193-PW). Both laminates were made by Hexcel Composites, being the epoxy matrix 8552 and the carbon fibre AS4; the composite fragment size was $150 \times 42 \times 11 \mathrm{~mm}^{3}$, and its mass 110 grams. The impact velocity varies from 140 to $180 \mathrm{~m} / \mathrm{s}$, since is the range in which the ballistic limit was expected to be. The ply sequences were:

- Unidirectional (UD): [(45/-45/0/-45/90/0/0/90/45/0/-45/45) *2+(45/-45/0/-45/90/0) $]_{\mathrm{S}}$

- Woven (2D): (45/-45/0/90/0/-45/45/0/90/0/45/-45/0/90)S']x 2

Finally, regarding the aluminium plate impacted, it is made from Al2024-T351, with a size of $300 \times 300 \mathrm{~mm}^{2}$ and a thickness of $4 \mathrm{~mm}$. The plate was clamped around its border leaving a free area of $280 \times 280 \mathrm{~mm}^{2}$.

\section{Results}

Figure 2 and 3 shows images of the aluminium panel impacted by a unidirectional composite fragment; the first one corresponds to a case with no penetration whereas in the second one a full penetration is observed. In both cases the fragment showed very little delamination, even if it was a unidirectional laminate with a quasi-isotropic orientation. The front face of the fragment appears slightly eroded due to the impact. Regarding the aluminium plate it presents a petaling failure pattern when impacted at enough velocity to promote penetration.
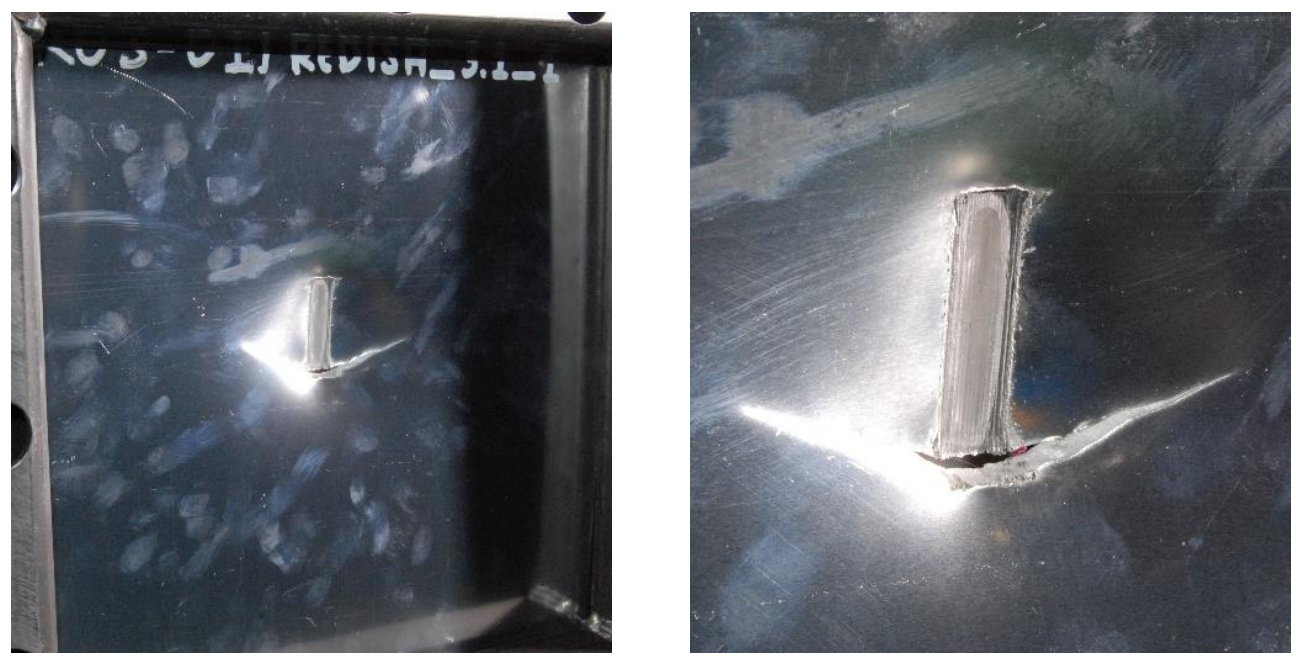

Fig. 2. Images of the high velocity impact of a UD fragment against an aluminium plate. Nonpenetration case.

Figure 4 shows the high velocity impact of a woven composite fragment; in this case the impact velocity was the corresponding to the ballistic limit, since the fragment gets stuck in the panel, being approximately half in each side. It is also possible to observe that the 
fragment does not exhibit any delamination, whereas a slightly erosion is identified in the front face.
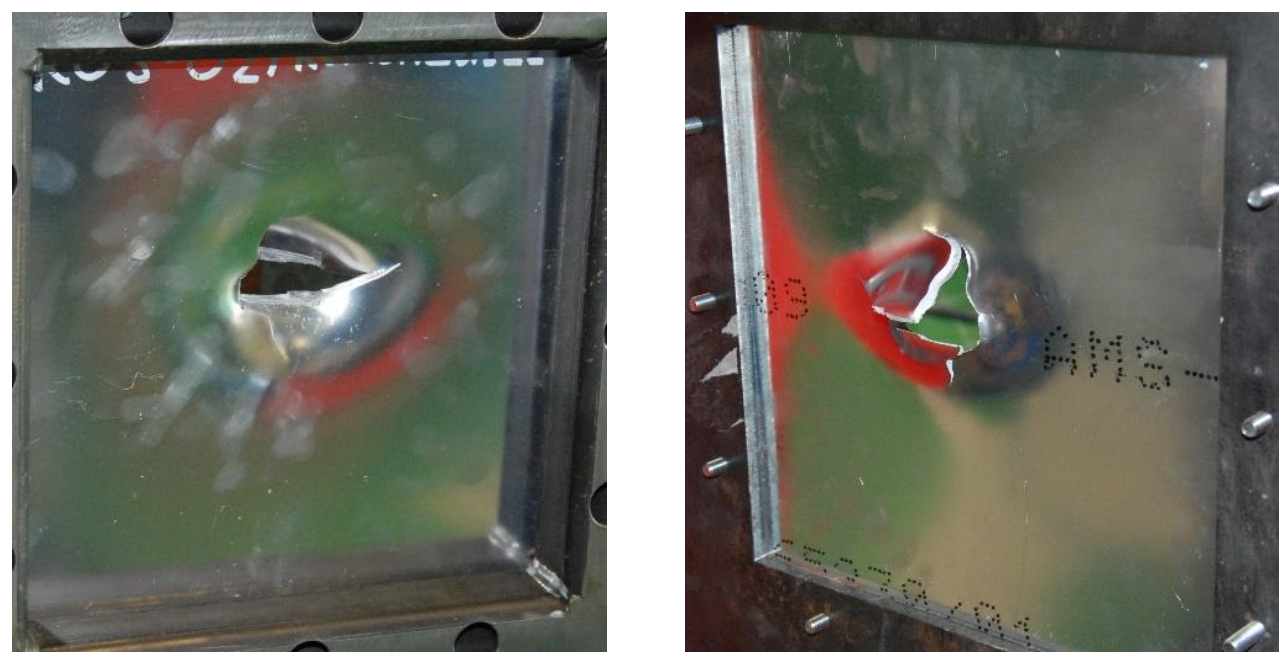

Fig. 3. Images of the high velocity impact of a UD fragment against an aluminium plate (front face and back face respectively). Penetration case.
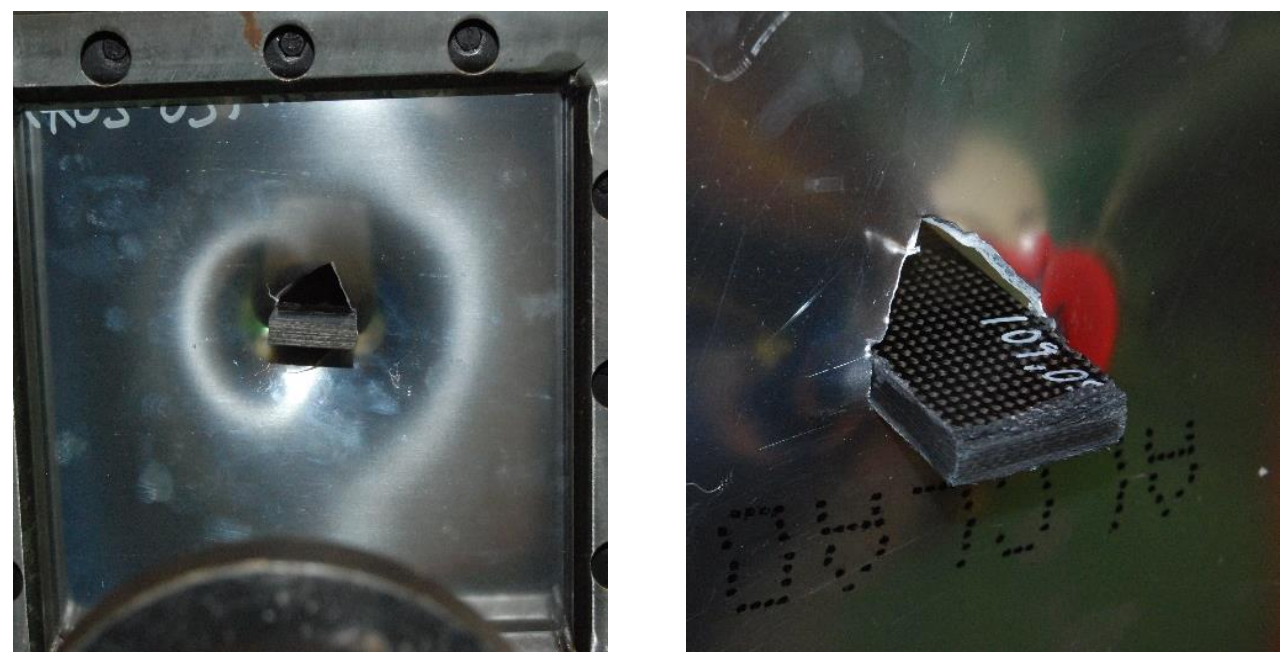

Fig. 4. Images of the high velocity impact of a woven fragment against an aluminium plate (front face and back face respectively). Non-penetration case.

Finally Figure 5 shows the impact velocity vs. the residual velocity for both fragments the ballistic limit is very close, $142 \mathrm{~m} / \mathrm{s}$ for the woven and $148 \mathrm{~m} / \mathrm{s}$ for the unidirectional. Nevertheless, if we analyse the impact at $148 \mathrm{~m} / \mathrm{s}$ for both impactors, it is clear that the penetration capacity of the woven is lower. It is possible to analyse the energy absorbed by the aluminium plate $\left(E_{c}\right)$, since is equal to the kinetic energy loosed by the projectile. Considering that the fragment mass is constant this value is:

$$
E_{c}=m\left(v_{i}^{2}-v_{r}^{2}\right)
$$


where $m$ is the projectile mass, $v_{i}$ is the fragment impact velocity and $v_{r}$ its residual velocity. The energy absorbed by the aluminium plate when the UD fragment is impacting is approximately $2200 \mathrm{~J}$. The $2 \mathrm{D}$ fragment by the other hand promotes that the aluminium absorbs $2400 \mathrm{~J}$. The reason of this behaviour could be related to the laminate strength. The UD fragment has $33 \%$ of its thickness with plies in the $0^{\circ}$ orientation (aligned with the impact direction). By the other hand 2D fragments has $27 \%$ of its thickness with fibres in the $0^{\circ}$ orientation ( 30 plies are at $0^{\circ}$ or $90^{\circ}$ of a total of 54 , the total has been divided by to since it is a plain-woven laminate). It is possible to state that the strength of the UD fragment is higher and hence facilitates the penetration process.

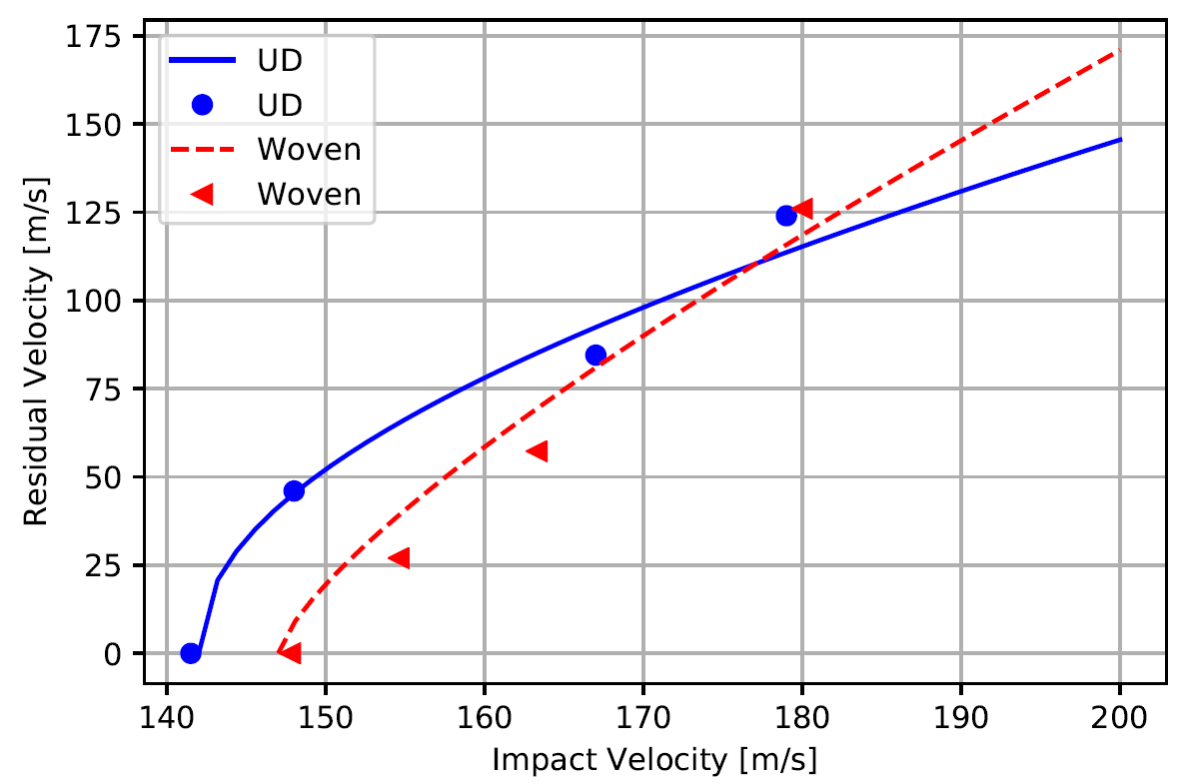

Fig. 5. Experimental curves of impact velocity vs. residual velocity for both composite fragments

\section{Conclusions}

In this work the experimental tests of high velocity impacts of composite fragments against aluminium plates is presented. Two different types of impactors were considered, unidirectional and woven, in order to evaluate its different penetration capacity. A square barrel has been conceived to launch the fragment (a rectangular prism) without rotation; a special sabot has also been developed to accelerate the impactor. The principal conclusions are the following:

- The fragments do not show any delamination after impact, only a small erosion is presented in the impact face. The aluminium plate presents a pataling failure pattern when impacted at high velocity (enough to promote the full penetration)

- For the studied configurations the ballistic limit was found to be around $145 \mathrm{~m} / \mathrm{s}$. The unidirectional fragment exhibits a slightly lower ballistic limit, which means that has a better penetration capacity.

- The reason of the higher penetration capacity of the unidirectional laminate compared to the woven could be related to its higher strength, since it has more fibres in the impact direction. 
This project has received funding from the Clean Sky 2 Joint Undertaking under the European Union's Horizon 2020 research and innovation programme under grant agreements No 715873 and No 686946 (which corresponds to the projects ELEMENT and REDISH respectively).

In Memoriam to Claudio Lopes, who sadly passed away recently.

\section{References}

1. W. Cantwell, J. Morton, Compos. Sci. Technol. 38: 119-41, (1990).

2. W. Cantwell, Compos. Struct. 10: 247-265 (1988).

3. W. Cantwell, J. Mater. Sci. Lett. 7: 756-758 (1988).

4. J. Chen, F. Allahdadi, T. Carney, Compos. Sci. Technol. 57: 1369-1379 (1997).

5. C. Ulven, U.K. Vaidya, M.V. Hosur, Compos. Struct. 61: 143-150 (2003).

6. S. Chan, Z. Fawaz, K. Behdinan, R. Amid, Compos. Struct. 77: 466-474 (2005).

7. E. Sevkat, Int. J. Impact. Eng. 45: 16-27 (2012).

8. J. López-Puente, R. Zaera, C. Navarro, Composites B. 33: 559-566 (2002).

9. J. López-Puente, R. Zaera, C. Navarro, J. Phys. IV 110: 639-644 (2003).

10. D. Fernández-Fdz, J. López-Puente, R. Zaera, Composites A. 39(6): 989-996 (2008).

11. J. A. Artero-Guerrero, J. Pernas-Sánchez, D. Varas, J. López-Puente, Compos. Struct. 96: 286-297 (2013).

12. J. A. Artero-Guerrero, J. Pernas-Sánchez, D. Varas, J. López-Puente, Compos. Struct. 107: $570-577$ (2014).

13. J. Pernas-Sánchez, J. A. Artero-Guerrero, D. Varas, J. López-Puente, Composites A. 60: 24-31 (2014).

14. J. A. Artero-Guerrero, J. Pernas-Sánchez, J. Martín-Montal, D. Varas, J. López-Puente, Compos. Struct. 183(1): 299-308 (2018).

15. J. Pernas-Sánchez, J. A. Artero-Guerrero, D. Varas, J. López-Puente, Exp. Mech. 55(9): 1669-1679 (2015).

16. J. Pernas-Sánchez, J. A. Artero-Guerrero, D. Varas, J. López-Puente, Int. J. Impact. Eng. 96: 1-10 (2016).

17. A.G. Mamalis, D.E. Manolakos, M.B. Ioannidis, D.P. Papapostolou, Compos. Struct. 69: 407-420 (2005).

18. A.G. Mamalis, D.E. Manolakos, M.B. Ioannidis, D.P. Papapostolou, Compos. Struct. 74: 213-225 (2005).

19. A. Mata-Díaz, J. López-Puente, D. Varas, J. Pernas-Sánchez, J.A. Artero-Guerrero, Int. J. Impact. Eng. 103: 231-240 (2017).

20. J. López-Puente, A. Mata-Díaz, J. Pernas-Sánchez, J.A. Artero-Guerrero, D. Varas, Compos. Struct. 203: 172-181 (2018). 